\title{
Cinnamaldehyde affects the biological behavior of human colorectal cancer cells and induces apoptosis via inhibition of the PI3K/Akt signaling pathway
}

\author{
JIEPIN LI ${ }^{1,2^{*}}$, YUHAO TENG ${ }^{1,2^{*}}$, SHENLIN LIU $^{1}$, ZIFAN WANG $^{3}$, YAN CHEN $^{1,2}$, YINGYING ZHANG $^{1,2}$, \\ SONGYANG XI ${ }^{1,2}$, SONG XU ${ }^{1,2}$, RUIPING WANG ${ }^{1}$ and XI ZOU ${ }^{1}$ \\ ${ }^{1}$ Department of Oncology, The Affiliated Hospital of Nanjing University of Chinese Medicine; \\ ${ }^{2}$ No. 1 Clinical Medical College, Nanjing University of Chinese Medicine, Nanjing, Jiangsu 210029, P.R. China; \\ ${ }^{3}$ Department of Commerce, The University of Melbourne, Victoria 3010, Australia
}

Received September 8, 2015; Accepted November 20, 2015

DOI: 10.3892/or.2015.4493

\begin{abstract}
Cinnamaldehyde (CA) is a bioactive compound isolated from the stem bark of Cinnamomum cassia, that has been identified as an antiproliferative substance with pro-apoptotic effects on various cancer cell lines in vitro. In the present study, the effects of CA on human colon cancer cells were investigated at both the molecular and cellular levels. Three types of colorectal cancer cells at various stages of differentiation and invasive ability (SW480, HCT116 and LoVo) were treated with CA at final concentrations of 20, 40 and $80 \mu \mathrm{g} / \mathrm{ml}$ for $24 \mathrm{~h}$. Compared with the control group, the proliferation inhibition rate of the human colorectal cancer cells following treatment with CA increased in a dose- and time-dependent manner. The invasion and adhesion abilities of the cells were significantly inhibited as indicated by Transwell and cell-matrix adhesion assays. Meanwhile, CA also upregulated the expression of E-cadherin and downregulated the expression of matrix metalloproteinase-2 (MMP-2) and MMP-9. CA also elevated the apoptotic rate. The levels of pro-apoptotic genes were upregulated while the levels of apoptosis inhibitory genes were decreased which further confirmed the pro-apoptotic effect of CA. In order to explore the mechanism of CA-induced apoptosis, insulin-like growth factor-1 (IGF-1) and PI3K inhibitor (LY294002) were used to regulate the phosphoinositide 3-kinase (PI3K)/AKT
\end{abstract}

Correspondence to: Professor Ruiping Wang or Professor Xi Zou, Department of Oncology, The Affiliated Hospital of Nanjing University of Chinese Medicine, 155 Hanzhong Road, Nanjing, Jiangsu 210029, P.R. China

E-mail:wrp61@163.com; ruipingwang61@hotmail.com

E-mail: zxvery@126.com

${ }^{*}$ Contributed equally

Key words: colorectal cancer, cinnamaldehyde, PI3K/AKT pathway, apoptosis pathway. The transcription activity of PI3K/AKT was markedly inhibited by CA, as well as IGF-1 which functions as an anti-apoptotic factor. In conclusion, CA has the potential to be developed as a new antitumor drug. The mechanisms of action involve the regulation of expression of genes involved in apoptosis, invasion and adhesion via inhibition of the PI3K/ Akt signaling pathway.

\section{Introduction}

Colorectal cancer (CRC) is one of the most common malignant tumors of the digestive system and is also one of the leading causes of cancer-related deaths worldwide (1). Early symptoms of CRC are usually not detected. Once diagnosed, CRC is often in the advanced stage, including metastasis to liver in the $20 \%$ of cases (2). The principle therapeutic method is surgery, as well as radiotherapy and chemotherapy (3). Although surgical techniques have been rapidly developed during the past few years, the 5-year survival rate of CRC patients has not significantly increased. Non-surgical therapies, such as chemotherapy and radiotherapy, lack efficacy. Currently, with advantages and achievements in the clinic, more and more active antitumor ingredients derived from Traditional Chinese medicine (TCM) are being developed, studied and used.

Cinnamaldehyde (CA), as shown in Fig. 1A, is a bioactive compound isolated from the stem bark of Cinnamomum cassia, and has been used as a TCM herb. Studies have demonstrated that CA displays various biological activities, including antibacterial, immunomodulatory, cytotoxic and anti-angiogenic activities (4-7). It is also known to possess marked antitumor effects in vitro and in vivo (8-11). However, the signaling mechanisms involved in the inhibition of CRC cell growth by CA are poorly understood.

The molecular mechanisms involved in the tumorigenesis and metastasis of CRC are not entirely clear. Carcinogenesis of CRC is complex and requires the accumulated alteration of multiple genes and pathways. The phosphoinositide-3-kinase (PI3K)/AKT signaling pathway is indispensable to intracellular signal transduction which involves cell metabolism, apoptosis, survival, differentiation and proliferation processes. 
Therefore, it is closely related to the occurrence, development and metastasis of many types of tumors (12). AKT and p-AKT are expressed in CRC tissues at a significantly higher level than those noted in normal tissues (13). This causes not only cell malignant transformation, but also tumor cell migration, adhesion and extracellular matrix degradation $(14,15)$. Therefore, the PI3K/Akt pathway is considered to be a potential target for cancer treatment and needs further research. Compounds that inhibit PI3K/AKT-related genes with drug-like properties blocking the activation of multiple downstream anti-apoptotic effector molecules and promoting cell apoptosis are highly anticipated.

In the present study, we investigated the effect of CA on cell proliferation, invasion and adhesion, and apoptosis of CRC cells. In addition, we aimed to study the mechanisms behind the effect of CA on the PI3K/AKT signaling pathway in order to provide an experimental foundation for the present research and a possible treatment of CRC.

\section{Materials and methods}

Drugs and antibodies. CA was purchased from the China National Institute for the Control of Pharmaceutical and Biological Products (purity 99\%) and dissolved in dimethylsulfoxide (DMSO). It was dissolved in DMSO at a stock solution $(200 \mu \mathrm{g} / \mathrm{ml})$ and stored at $-80^{\circ} \mathrm{C}$. 3-(4,5-Dimethylthiazol-2yl)-2,5-diphenyltetrazolium bromide (MTT) was purchased from Sigma Chemical Co. (St. Louis, MO, USA). Annexin V conjugated to fluorescein-isothiocyanate (Annexin V-FITC) apoptosis detection kit was purchased from KeyGen Biotech. Co. Ltd. (Nanjing, China). Insulin-like growth factor-I (IGF-I) was obtained from PeproTech China (Suzhou, China). Rabbit anti-human antibodies against MMP-9, MMP-2, E-cadherin, Bax, Bcl-2, PARP, cleaved-PARP, PI3K p-PI3K, AKT, p-AKT and LY294002 (the PI3K inhibitor) were purchased from Cell Signaling Technology (Beverly, MA, USA). Fluoresceinconjugated secondary antibodies were purchased from Odyssey (LI-COR, Lincoln, NE, USA). All other chemicals used in the experiment were of the highest purity grade available.

Cell lines and culture. Human CRC cell lines LoVo, SW480 and HCT116 were obtained from the Type Culture Collection, Chinese Academy of Sciences (Shanghai, China). All the cells were cultured in RPMI-1640 medium containing 10\% heatinactivated fetal bovine serum (FBS) (both from Gibco-BRL, Gaithersburg, MD, USA) in a humidified incubator with 5\% $\mathrm{CO}_{2}$ at $37^{\circ} \mathrm{C}$.

MTT assay. Cells in the logarithmic growth phase were firstly seeded into 96 -well culture plates at $6 \times 10^{3}$ cells/well and then incubated overnight following treatment of CA at concentrations of $0,20,40,60$ and $80 \mu \mathrm{g} / \mathrm{ml}$ for 24,48 and $72 \mathrm{~h}$. Afterwards, $20 \mu \mathrm{l}$ of MTT solution $(5 \mathrm{mg} / \mathrm{ml})$ was added to each well to incubate the cells at $37^{\circ} \mathrm{C}$ for $4 \mathrm{~h}$. In order to dissolve the resultant formazan crystals, $100 \mu$ DMSO was added to each well. Absorbance was detected at $490 \mathrm{~nm}$ using an ELx800 microplate reader (BioTek, Winooski, VT, USA). Cell growth inhibition rate was calculated using the following formula: 1 - $\mathrm{OD}_{\text {experiment }} / \mathrm{OD}_{\text {control}}$.
Cell apoptosis assay. Apoptosis was monitored using the Annexin V/propidium iodide (PI) method as previously described (16), and its rate was detected by flow cytometry with an Annexin V-FITC apoptosis detection kit. The cells were seeded in 6-well plates and treated with CA $(0,20,40$ and $80 \mu \mathrm{g} / \mathrm{l}$ ) for $24 \mathrm{~h}$, and then harvested by trypsinization. After washing twice with cold phosphate-buffered saline (PBS), the cells were re-suspended in $500 \mu \mathrm{l}$ binding buffer at $1 \times 10^{6}$ cells $/ \mathrm{ml}$. Annexin V-FITC (5 $\left.\mu \mathrm{l}\right)$ PI was subsequently added for incubation at room temperature for $15 \mathrm{~min}$.

Hoechst 33258 staining. Hoechst 33258 staining was performed as previously described (17). HCT116, LoVo and SW480 cells were fixed with $4 \%$ paraformaldehyde for $30 \mathrm{~min}$ after treatment with CA for $24 \mathrm{~h}$ at room temperature and washed once with PBS. Cells were incubated in Hoechst 33258 $(50 \mathrm{ng} / \mathrm{ml})$ for $30 \mathrm{~min}$ at room temperature and then washed with PBS. Apoptotic cells were identified by the condensation and fragmentation of their nuclei and photographed by a Zeiss Axioplan 2 fluorescence microscope (Jena, Germany).

Invasion assay. The cell migration assay was performed using Transwell membrane filter inserts (pore size, $8-\mu \mathrm{m}$; Costar, Corning, NY, USA) in 24-well dishes. The cells were pretreated for $24 \mathrm{~h}$ with different concentrations of CA. Approximately $1 \times 10^{4}$ cells in $200 \mu 1$ of serum-free medium were placed in the upper chamber, and $300 \mu \mathrm{l}$ of the medium containing $10 \%$ bovine serum was placed in the lower chamber. The plates were incubated for $24 \mathrm{~h}$ at $37^{\circ} \mathrm{C}$ in $5 \% \mathrm{CO}_{2}$, and the cells were then fixed in $4 \%$ paraformaldehyde for $5 \mathrm{~min}$ and stained with $0.05 \%$ crystal violet (Sigma-Aldrich, St. Louis, MO, USA) in PBS for $15 \mathrm{~min}$. Cells on the upper side of the filters were removed with cotton-tipped swabs, and those on the underside of the filters were examined and counted under a microscope as previously described (18).

Cell-matrix adhesion assay. The cell adhesion assay was performed as previously described (19). Briefly, CRC cells were treated with or without CA $(20,40$ or $80 \mu \mathrm{g} / \mathrm{ml})$ for $24 \mathrm{~h}$, and then harvested and resuspended in RPMI-1640 medium. Approximately $2 \times 10^{5}$ live cells were seeded into precoated 96-well plates with $2.5 \mu \mathrm{g} / \mathrm{ml}$ fibronectin (FN). Each concentration group contained 12-wells and every 3-wells were washed twice after 30, 60, 90 and $120 \mathrm{~min}$ to remove the non-adherent cells. After washing with PBS, the adherent cells were measured by an MTT assay. Similar to the MTT assay, optical density (OD) values were measured and the cell adhesion inhibition rates were calculated based on the means of three wells.

Western blot analysis. Western blot analysis was performed according to the method reported by Li et al with slight modification (20). The cells were lysed in RIPA buffer in an ice bath for $20 \mathrm{~min}$, and centrifuged at $12,000 \mathrm{x} \mathrm{g}$ for $10 \mathrm{~min}$ at $4^{\circ} \mathrm{C}$. The supernatant was stored at $-80^{\circ} \mathrm{C}$ until analyses. The protein concentration was measured using the BCA method (Beyotime). An equal amount of proteins was loaded onto $10 \%$ SDS-polyacrylamide gel for electrophoresis and transferred by electroblotting to a polyvinylidene difluoride membrane (Millipore, Boston, MA, USA), which was blocked with 5\% 

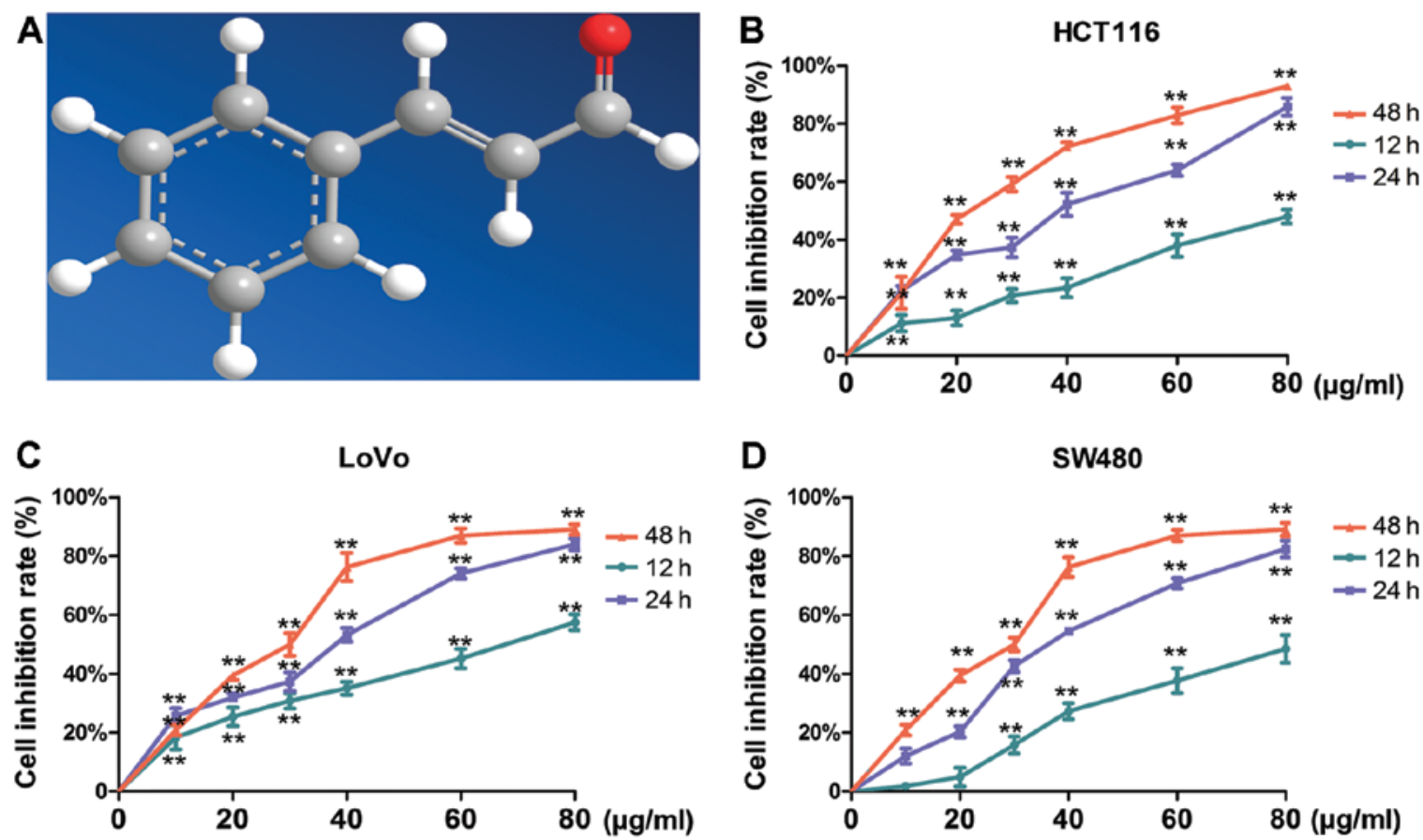

Figure 1. Effects of cinnamaldehyde (CA) on the cell growth inhibition rate of colorectal cancer (CRC) cells. (A) Model of the chemical structure of cinnamaldehyde. (B) HCT116, (C) LoVo and (D) SW480 cells were treated with 0, 10, 20,30, 40,60 and $80 \mu \mathrm{g} / \mathrm{ml}$ of CA for 12, 24 and 48 h. The cell growth inhibitory rate was measured using an MTT assay. The results from three independent experiments are represented in the form of means $\pm \mathrm{SD}$. ${ }^{* * *} \mathrm{p}<0.01$ compared with the control group.

BSA, and then incubated with the indicated primary antibodies against MMP-9, MMP-2, E-cadherin, Bax, Bcl-2, PARP, cleaved-PARP, PI3K AKT, $(1: 1,000)$, p-PI3K and p-AKT (1:500) at $4^{\circ} \mathrm{C}$ overnight. After washing with Tris-buffered saline with Tween-20 (TBST) for three times (5 min/time), secondary fluorescent antibody (1:2,000 dilutions) was added to the membrane at room temperature for $1 \mathrm{~h}$. The signal intensity of the OD of each band on the membrane was detected by Odyssey (LI-COR) ImageJ analyzer software; $\beta$-actin was used as loading control and for normalization.

Statistical analysis. All data are presented as means \pm standard deviation (SD). Statistical analysis was performed by SPSS 19.0 software with one-way ANOVA followed by Dunnet's test to compare the treatment and the control groups. A p-value of $\leq 0.05$ was considered to indicate a statistically significant result.

\section{Results}

Effects of CA on the cell inhibition rate of human CRC cells. It is well-known that uncontrolled proliferation is the major malignant characteristic of cancer cells. In the present study, we first tested whether CA inhibits CRC cell proliferation in vitro. After treatment with 0, 10, 20,30, 40, 60 and $80 \mu \mathrm{g} / \mathrm{ml}$ of CA for 12, 24 and $48 \mathrm{~h}$, the effect of different concentrations on the inhibition rate of the cells was observed using the MTT assay. As shown in Fig. 1B-D, the inhibition rates of the cells were significantly higher compared with the control group at the same time points $(\mathrm{p}<0.01)$, and the inhibition by $\mathrm{CA}$ was exhibited in an approximate dose- and time-dependent manner. Twenty-four hours were found to be the optimal administration time for the next study. The $\mathrm{IC}_{50}$ values of $\mathrm{CA}$ inhibition of HCT116, LoVo and SW480 cell growth at $24 \mathrm{~h}$ were $30.7,30.6$ and $35.69 \mu \mathrm{g} / \mathrm{ml}$, respectively.

CA induces the apoptosis of human CRC cells. Apoptosis is a highly regulated process and is regulated by a series of genes and cell-signaling pathways. To further confirm whether CA induces apoptosis in CRC cells, we evaluated the effects of CA on CRC cells using Annexin V-FITC and observed the nuclear morphological changes in cells using Hoechst 33258 staining. The results (Fig. 2) indicated that the rates of early and late apoptosis in the cells were increase by CA, and the apoptotic rates following treatment with 20,40 and $80 \mu \mathrm{g} / \mathrm{ml}$ of CA were significantly higher than the rates in the control group. Cell morphological change was assessed by fluorescence microscopy after staining with Hoechst 33258. The apoptotic cells (Fig. 3, indicated with arrows) exhibited highly fluorescent condensed chromatin. In the treated cells, we observed small, fragmented and condensed nuclei with typical apoptotic morphology in contrast with normal symmetrical, blue nuclei (Fig. 3).

CA induces apoptosis via regulation of apoptosis-related genes in human CRC cells. It is well-known that proteins of the Bcl-2 family and PARP are influential in the apoptotic process (21). Targeting the proteins of the Bcl-2 family is a common practice for many anticancer agents inducing apoptosis and the ratio of $\mathrm{Bax} / \mathrm{Bcl}-2$ also plays a critical role (22). In order to study the molecular mechanisms behind the CA-induced apoptosis of human CRC cells, the expression levels of apoptosis-related proteins were evaluated by western blot analysis after treatment with various concentrations of 

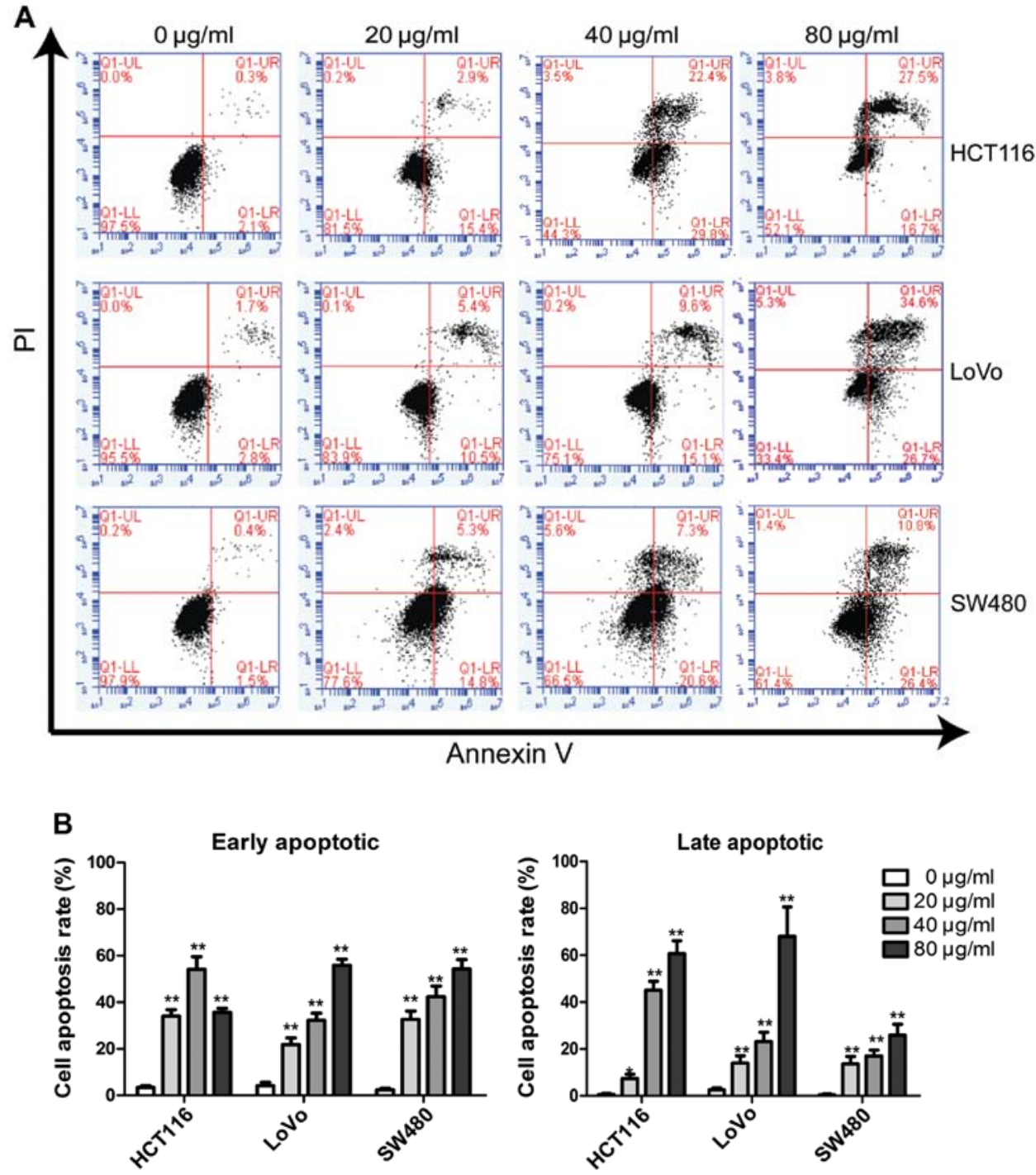

Figure 2. Cinnamaldehyde (CA) induces the apoptosis of colorectal cancer (CRC) cells. (A) Flow cytometric analysis. (B) Cell apoptosis rate. After treatment with $0,20,40$ and $80 \mu \mathrm{g} / \mathrm{ml}$ of CA for $24 \mathrm{~h}$, the cells were stained with FITC-conjugated Annexin V and PI for flow cytometric analysis. The results from three independent experiments are represented in the form of means $\pm \mathrm{SD} .{ }^{* *} \mathrm{p}<0.01$ compared with the control.
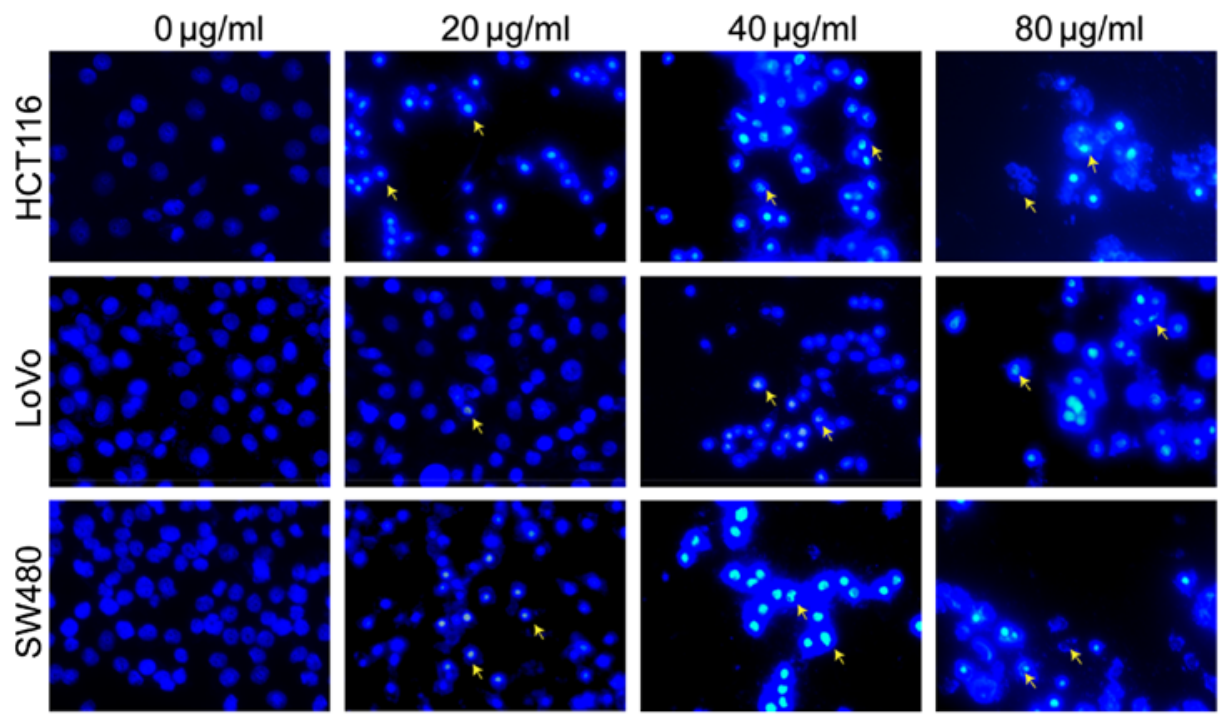

Figure 3. Effect of cinnamaldehyde (CA) on morphological changes in colorectal cancer (CRC) cells. After treatment with $0,20,40 \mathrm{and} 80 \mu \mathrm{g} / \mathrm{ml}$ of CA for $24 \mathrm{~h}, \mathrm{CRC}$ cells were stained with Hoechst 33258 and morphological changes were observed with fluorescent microscope. Arrowheads indicate the cells with abnormal nuclei, indicating fragmentation of nuclei/chromatin. Magnification, x200. 
A
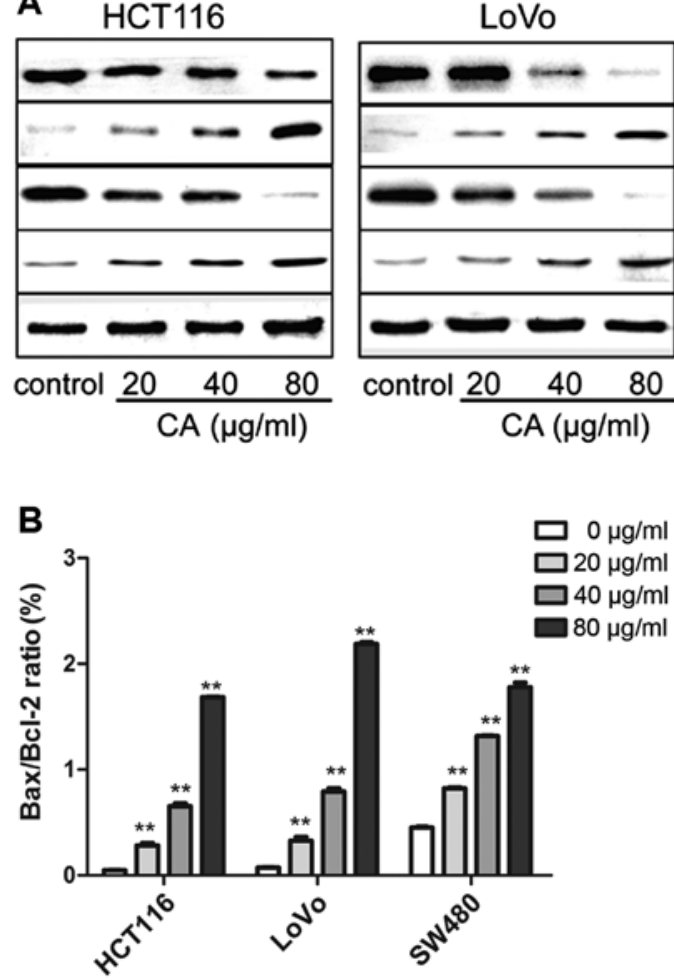

LoVo

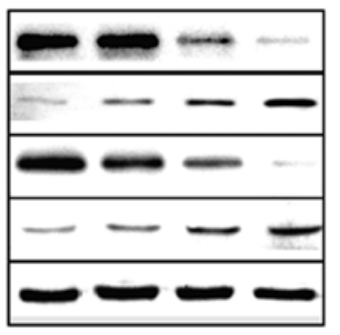

control $20 \quad 40 \quad 80$

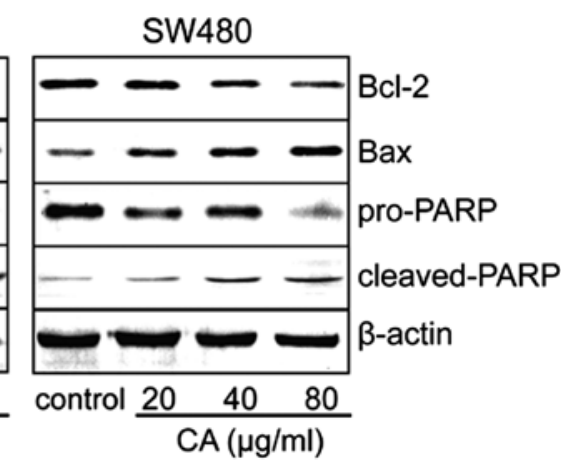

Figure 4. Cinnamaldehyde (CA) induces apoptosis via regulation of apoptosis-related genes. (A) Cells were treated with CA $(0,20,40$ and $80 \mu \mathrm{g} / \mathrm{ml})$ for $24 \mathrm{~h}$. The expression levels of Bcl-2, Bax, cleaved-PARP and PARP were detected by western blot analysis, and $\beta$-actin was used as a loading control. (B) The levels of Bax and Bcl-2 were measured by densitometric analysis in order to evaluate the effect of $\mathrm{CA}$ on the $\mathrm{Bax} / \mathrm{Bcl}-2$ ratio. The results from three independent experiments are represented in the form of means $\pm \mathrm{SD}$. ${ }^{* *} \mathrm{p}<0.01$ compared with the control group.

CA for $24 \mathrm{~h}$. Western blot analysis revealed that the Bax and cleaved-PARP expression was obviously increased, whereas PARP and Bcl-2 expression was decreased, leading to an upregulation in the ratio of $\mathrm{Bax} / \mathrm{Bcl}-2$ (Fig. 4). This may be one of the molecular mechanisms by which CA induces apoptosis in CRC cells.

CA inhibits CRC cell invasion and adhesion. We used Transwell chamber and cell-matrix adhesion assays to test whether CA inhibits CRC cell invasion and adhesion. As shown in Fig. 5, the result of the Transwell assay showed that after treatment with different concentrations of CA $(0,20,40$ and $80 \mu \mathrm{g} / \mathrm{ml}$ ) for $24 \mathrm{~h}$, the number of the cells that invaded across the $8-\mu \mathrm{m}$ diameter pores to the lower chamber was markedly decreased compared with the number of invasive cells in the control group, indicating that CA suppresses the invasion of CRC cells in a dose-dependent manner (Fig. 5B). The results indicated that increasing CA concentrations promoted an increased inhibition of cell invasion.

Meanwhile, similar to the results of the Transwell invasion assay, the adhesion rates of the cells treated with CA at all time points were lower than those of the control group. Further data demonstrated that the inhibitory rate of adhesion escalated as the concentrations of CA increased (Fig. 6). Consequently, CA markedly inhibited the adhesion of CRC cells to FN and the inhibition rate exhibited a dose- and time-dependent trend.

Effects of CA on expression of invasion- and adhesionrelated genes in human $C R C$ cells. We investigated the expression of E-cadherin and MMP-2 and MMP-9 in the CRC cells to explore whether changes in the expression were involved in the inhibition of invasion and adhesion of these cells. E-cadherin, a member of the cadherin superfamily, is involved in maintaining cell polarity and organizing the epithelium by strengthening intercellular adhesion; and is also closely associated to invasion in an MMP2-dependent manner (23). In addition to adhesion molecules, matrix metalloproteinases (MMPs) have the ability to degrade extracellular matrix (ECM) proteins and influence cell behaviors, including invasion and differentiation. Among the MMPs mentioned above, the activity of two gelatinases, MMP-2 and MMP-9, was found to be closely related with tumor metastasis in particular (24-26). Western blotting was used to analyze the levels of E-cadherin, MMP-2 and MMP-9. As shown in Fig. 7, CA significantly reduced the expression of MMP-2 and MMP-9 in a concentration-dependent manner. Expression of E-cadherin was upregulated as the dose of CA increased which may be responsible for the reduction in cell invasion and adhesion observed in the CRC cells.

Effects of CA on the PI3K/Akt signaling pathway in human CRC cells. The PI3K/Akt signaling pathway participates in regulating cell biological behaviors. It has been reported to inhibit cellular apoptosis and promote cell survival (27). Thus, for many chemotherapeutic drugs, their antitumor effects are achieved by blocking this pathway $(28,29)$. Phosphorylated PI3K and Akt are attractive molecular targets as they contribute to the development of human CRC and resistance to conventional therapies. Therefore, the potential role of CA on the PI3K/Akt signaling pathway was examined.

In the present study, the cells were pretreated with insulinlike growth factor-1 (IGF-1) (one of the most potent activators of the PI3K/Akt signaling pathway) for $2 \mathrm{~h}$ in order to activate the PI3K/Akt signaling pathway, and then treated with $40 \mu \mathrm{g} /$ $\mathrm{ml} \mathrm{CA}$ for $24 \mathrm{~h}$ (30). To further confirm the results, CRC cells were pretreated with IGF-I for $2 \mathrm{~h}$, followed by exposure to 
A
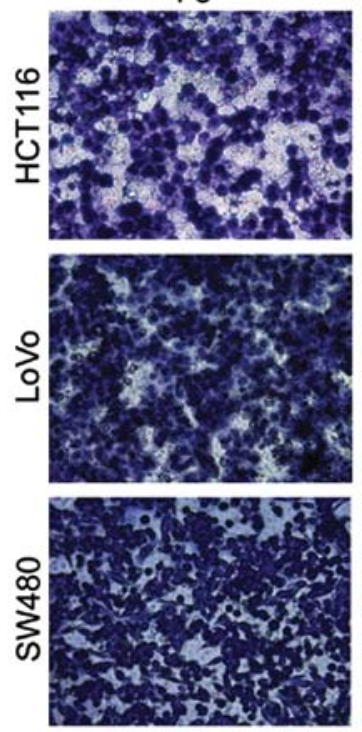

$20 \mu \mathrm{g} / \mathrm{ml}$
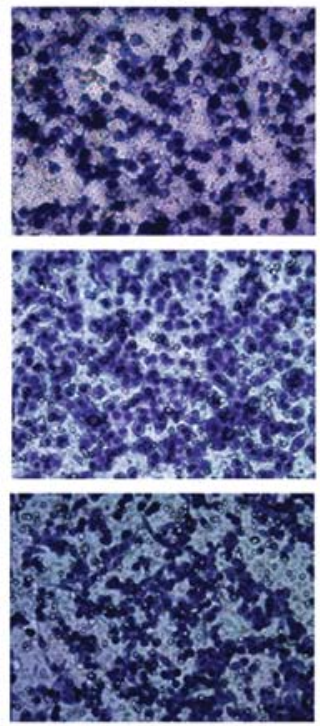

$40 \mu \mathrm{g} / \mathrm{ml}$
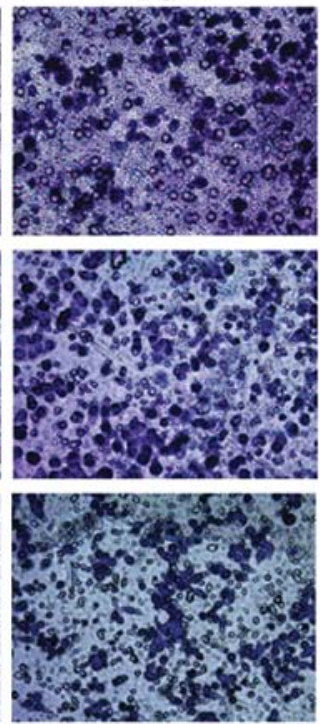

$80 \mu \mathrm{g} / \mathrm{ml}$
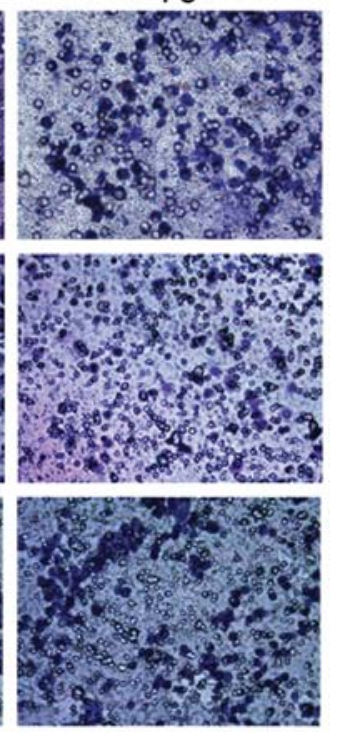

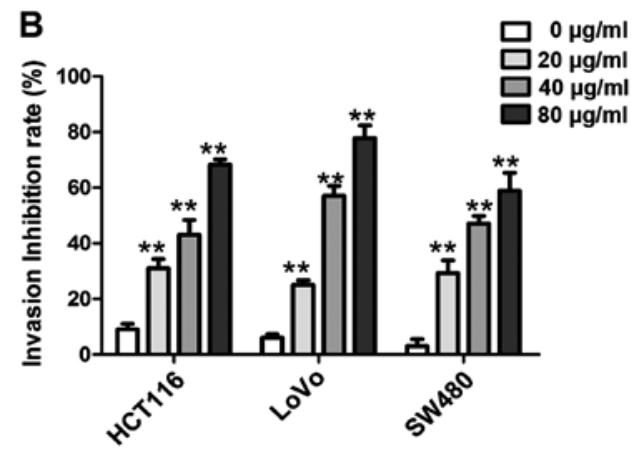

Figure 5. The effects of cinnamaldehyde (CA) on the invasive ability of the CRC cells as determined by Transwell assay. (A) After treatment with different concentrations of CA, images of the cells that migrated across the $8-\mu \mathrm{m}$ diameter pores to the lower chamber at $24 \mathrm{~h}$, were captured by light microscopy (magnification, $\mathrm{x} 400$ ). The white dots are the $8-\mu \mathrm{m}$ diameter pores of the Transwell chamber. (B) Columns indicate the invasion inhibition rate of CA on the CRC cells at different concentrations, respectively. The results from three independent experiments are represented in the form of means \pm SD. ${ }^{* *} \mathrm{p}<0.01$ compared with the control group.
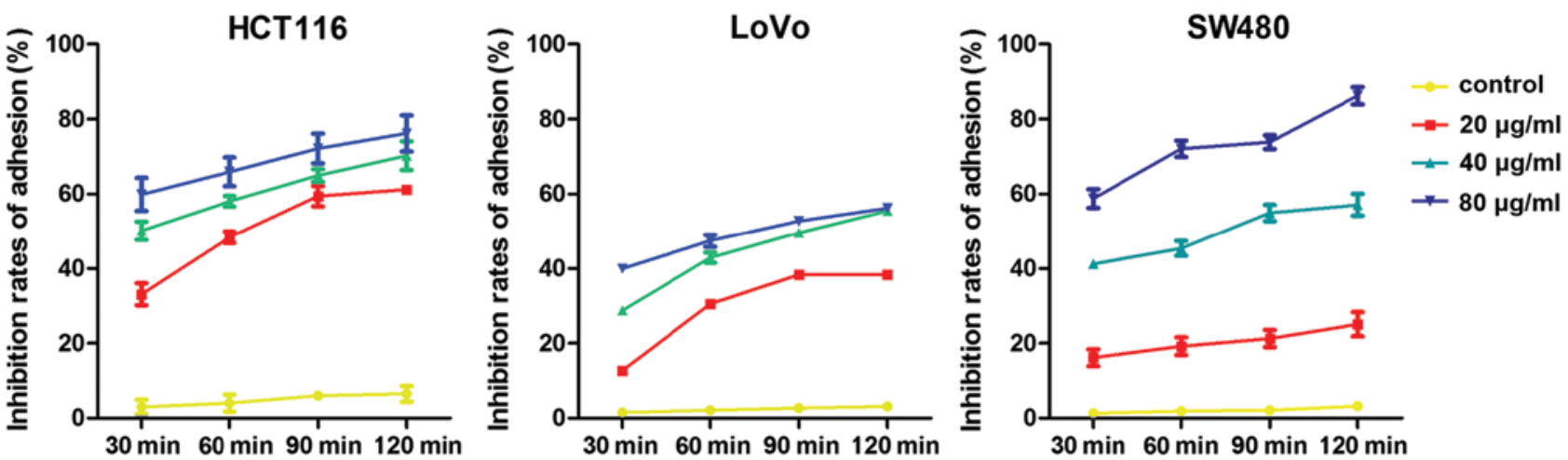

Figure 6. Cell-matrix adhesion assay was used to detect the effect of cinnamaldehyde (CA) on the adhesion ability of the colorectal cancer (CRC) cells. Each point on the curve indicates the inhibition rate of cell adhesion following treatment with different concentrations $(0,20,40 \mathrm{and} 80 \mu \mathrm{g} / \mathrm{ml})$ of CA at different time periods $(30,60,90$ and $120 \mathrm{~min})$.

the well-characterized pharmacological inhibitor LY294002 $(50 \mu \mathrm{M})($ a specific inhibitor of PI3K) for $24 \mathrm{~h}$ as a positive control (31). Western blot analysis indicated that CA inhibited IGF-1-induced expression of p-AKT protein. The total p-PI3K level was also inhibited although the total PI3K, total Akt level in each experimental group did not obviously change (Fig. 8). Taken together, CA inhibited the PI3K/Akt signaling pathway by downregulating $\mathrm{p}-\mathrm{PI} 3 \mathrm{~K}$ and $\mathrm{p}-\mathrm{AKT}$.

To confirm whether the apoptosis of CRC cells by CA was mainly regulated through the PI3K/Akt pathway, IGF-1 and
LY294002 were used to evaluate the underlying mechanisms. Recent studies indicate that IGF-1 not only acts as an insulin and mediates the growth hormone action, but also can inhibit apoptosis (32). The PI3K/Akt pathway is implicated in the entire spectrum of IGF-1-induced anti-apoptotic mechanisms (33). The results indicated that the IGF-1-induced anti-apoptotic effect was inhibited by LY294002 and CA (Fig. 9). Taken together, CA downregulate PI3K/Akt-dependent transcriptional activity, resulting in the regulation of apoptosis-related gene expression. 

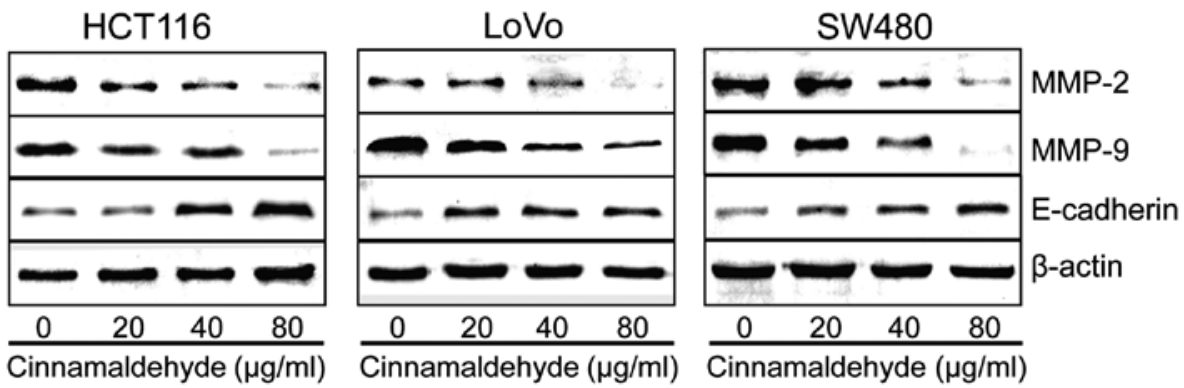

Figure 7. Cinnamaldehyde (CA) suppresses MMP-2 and MMP-9 expression while increasing E-cadherin expression. Colorectal cancer (CRC) cells were treated with CA at different concentrations for $24 \mathrm{~h}$. The expression levels of E-cadherin, MMP-2 and MMP-9 were detected by western blot analysis, $\beta$-actin was used as a loading control.
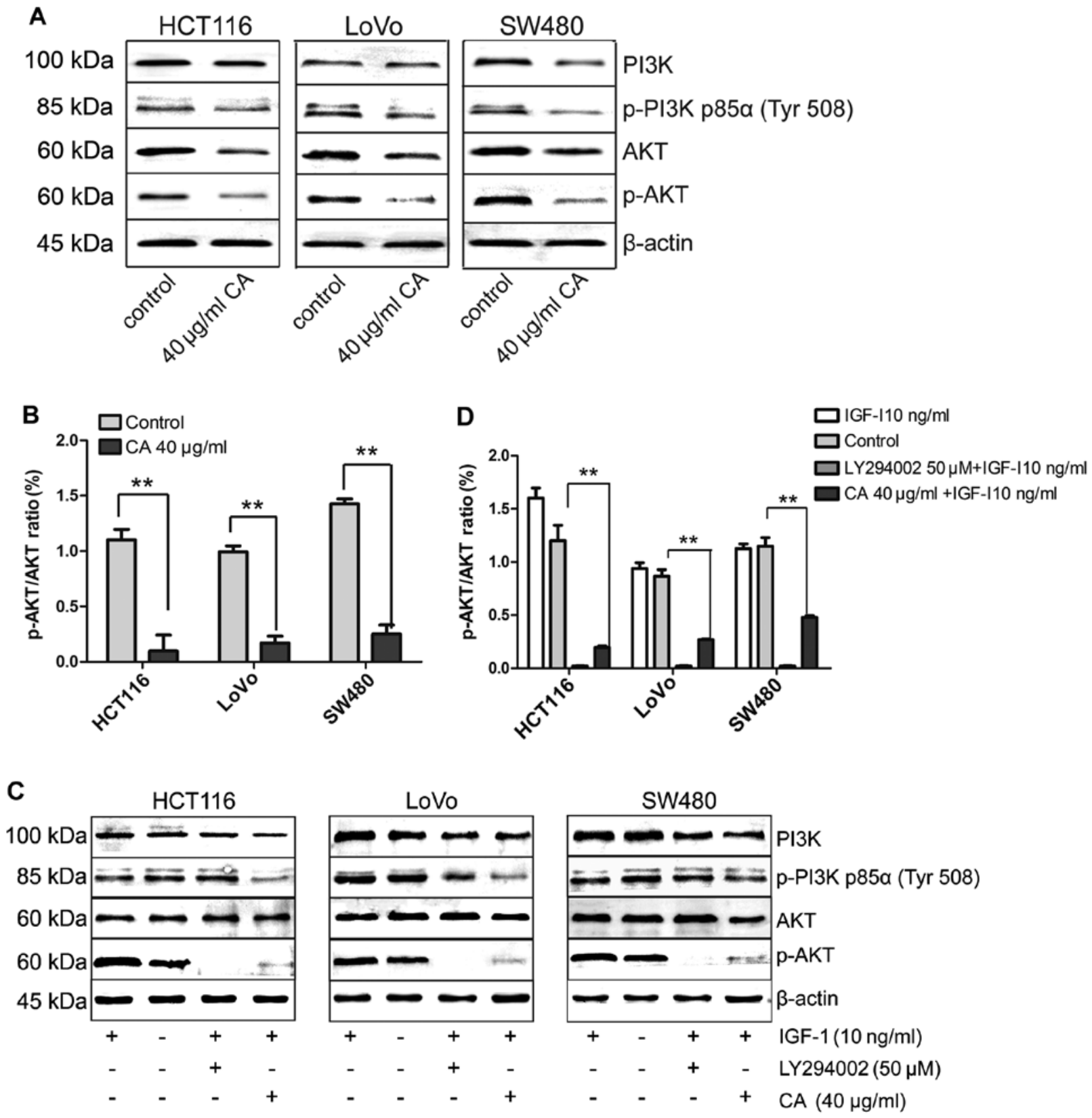

Figure 8. Effects of cinnamaldehyde (CA) on the PI3K/Akt signaling pathway in human colorectal cancer cells. (A) Cells were treated with $40 \mu \mathrm{g} / \mathrm{ml} \mathrm{CA}$ alone, and the expression of PI3K, p-PI3K, Akt and p-Akt was detected by western blot analysis. $\beta$-actin was used as a loading control. (B) Densitometric analysis was used to evaluate the p-AKT/AKT ratio. (C) Cells were pretreated with $10 \mathrm{ng} / \mathrm{ml}$ IGF-I for $2 \mathrm{~h}$, and then treated with $40 \mu \mathrm{g} / \mathrm{ml} \mathrm{CA}$. The cells were also pretreated with IGF-I for $2 \mathrm{~h}$, followed by exposure to LY294002 for $24 \mathrm{~h}$ as a positive control. The expression of PI3K, p-PI3K, Akt and p-Akt was detected by western blot analysis. $\beta$-actin was used as a loading control. (D) Densitometric analysis was used to evaluate the p-AKT/AKT ratio. The results from three independent experiments are represented in the form of means \pm SD. ${ }^{* *} \mathrm{p}<0.01$ compared with the control group. 

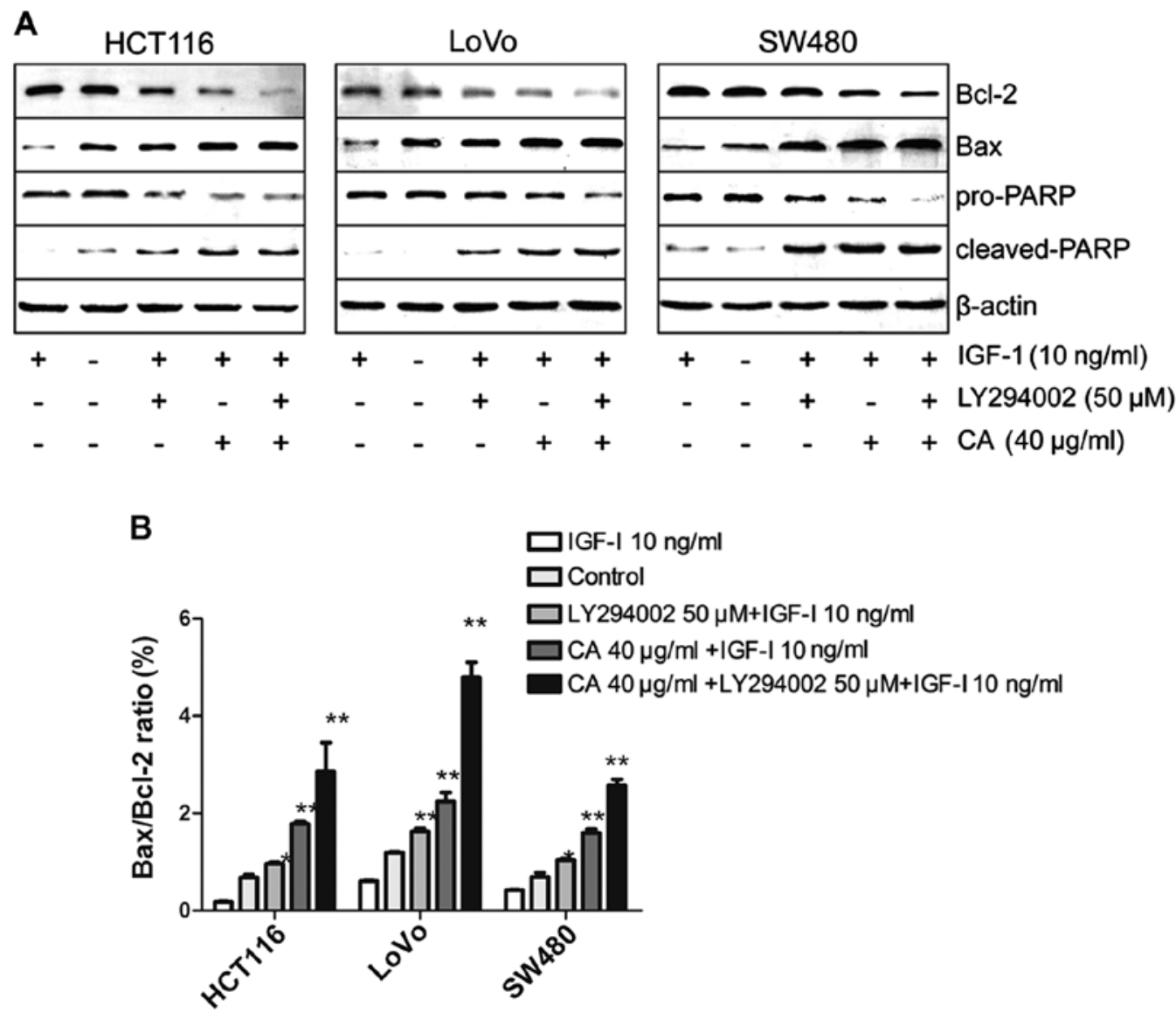

Figure 9. PI3K/AKT signaling pathway is involved in cinnamaldehyde (CA)-induced apoptosis. Cells were pretreated with $10 \mathrm{ng} / \mathrm{ml} \mathrm{IGF}-\mathrm{I}$ for $2 \mathrm{~h}$, and then treated with $40 \mu \mathrm{g} / \mathrm{ml} \mathrm{CA}$. The cells were also exposed to $50 \mu \mathrm{M}$ of LY294002 for $24 \mathrm{~h}$ as a positive control. (A) The expression levels of Bcl-2, Bax, cleaved-PARP and PARP were detected by western blot analysis, and $\beta$-actin was used as a loading control. (B) Densitometric analysis was used to quantify the levels of $\mathrm{Bax}$ and $\mathrm{Bcl}-2$ to evaluate the effect of $\mathrm{CA}$ on the $\mathrm{Bax} / \mathrm{Bcl}-2$ ratio. The results from three independent experiments are represented in the form of means $\pm \mathrm{SD}$. ${ }^{* *} \mathrm{p}<0.01$ compared with the control group.

\section{Discussion}

In recent years, with advances in treatment, the survival rate of colorectal cancer (CRC) patients has increased. However, many patients still relapse after surgery, radiotherapy and chemotherapy. Thus preventing the recurrence and metastasis of CRC is one of the focuses of the present study. Resistance of cell death, increased invasion and metastasis ability, and selfsufficiency in growth signals are intrinsic characteristics of all types of carcinomas (34), including CRC. Based on these facts, three types of CRC cells with different differentiation stage and invasive ability were selected for the present research.

CA has attracted a great deal of research interest for its anticancer properties. It has been used to inhibit the growth and induce the apoptosis of cancer cells as a natural bioactive substance in several studies. Its potential in the development of an effective anticancer and chemopreventive agent has been a focus in previous studies (35-37). However, research on the mechanism of CA against colon cancer is rare. Thus, we explored the effect of CA on apoptosis, invasion and metastasis of CRC cells and the related molecular mechanisms.

Resisting apoptosis is the principal mechanism by which tumor cells resist death, and it is an important point for the development of anticancer drugs. In the present study, we applied Annexin V-FITC/PI double staining and FCM (Fig. 2) and Hoechst staining (Fig. 3) to investigate the effects of CA on the apoptosis of human CRC cells. The results indicated that CA induced apoptosis at both the early and late stages.

Apotosis can be triggered by two signaling pathways, the extrinsic pathway (death receptor pathway) and the intrinsic pathway (the mitochondrial pathway) (38). Poly(ADP-ribose) polymerase (PARP) is a key signaling nuclear protein involved in apoptosis. Activated caspase protein cuts it into cleaved poly(ADP-ribose) polymerase which is a marker of the progression of apoptosis $(39,40)$. To further explore the molecular mechanisms, western blot analysis was used (Fig. 4). Then, we found that the protein level of PARP was decreased in a dose-dependent manner, while the c-PARP protein level was increased. The Bcl-2 family plays a significant part in apoptosis (41). Particularly, the stoichiometries of Bax (pro-apoptotic gene) and Bcl-2 (anti-apoptotic gene) are influential factors for the downstream activation of caspase protein $(42,43)$. Therefore, we continued to detect the expression change in Bcl-2 family members. We found that the ratio of Bax/Bcl-2 increased with increasing doses of CA. These results suggest that $\mathrm{CA}$ can regulate the ratio of $\mathrm{Bax} / \mathrm{Bcl}-2$ to induce apoptosis in human CRC cells.

In regards to invasion, it is the one of most critical and fatal characteristics of malignant tumors. Adhesion of tumor cells is an essential and initial step for tumor invasion and 
metastasis $(44,45)$. Research has shown that invasion and adhesion are mediated largely by MMPs, and among the MMPs, MMP-2 and MMP-9 are critical factors (46). However, no study has extensively explored the underlying mechanisms of the anti-adhesive, anti-invasive effects of CA. To test whether CA inhibits invasion and adhesion of CRC cells, Transwell chamber and cell-matrix adhesion assays were applied. We found that CA inhibited cell invasion (Fig. 5) and adhesion (Fig. 6) of human CRC cells in vitro. Meanwhile, we also found that the effectiveness of CA on cell invasion and adhesion was influenced by the inhibition of MMP-2 and MMP-9 activities in a dose-dependent manner (Fig. 7).

Self-sufficiency in growth signals is another characteristic of tumor cells. As one of the most important intracellular pathways, the PI3K/Akt pathway is frequently activated in a number of cancers and is responsible for cell growth, metabolism, proliferation, survival, motility and invasion. Furthermore, previous research found that high PI3K expression is associated with CRC metastasis (47-50). In the present study, it was discovered that CA effectively inhibited activation of the PI3K/AKT pathway (Fig. 8).

In previous research, many scholars found that IGF-1 is highly expressed in the serum of patients with CRC. Moreover, IGF-1 plays an important role in the pathogenesis and metastasis of CRC $(51,52)$. In the present study, we found that IGF-1 activated the PI3K/AKT signaling pathway in these three cell lines. To further confirm this, we treated the cells with CA or LY294002 (a specific inhibitor of PI3K). The results revealed that CA effectively inhibited activation of the PI3K/AKT pathway, and the efficiency of CA can basically approach the the efficacy of LY294002 (Fig. 9).

In conclusion, CA induces apoptosis and inhibits invasion and adhesion in CRC cells by inhibiting activation of the PI3K/ Akt pathway, and it is capable of antagonizing the activation of the PI3K/AKT signaling pathway by IGF-1. These findings provide an experimental basis for CA to be used as a drug for colon cancer; however, more basic research is needed to verify the antitumor activity of CA.

\section{Acknowledgements}

The present study was supported by the National Natural Scientific Foundation of China (no. 81473605), the Priority Academic Program Development of Jiangsu Higher Education Institutions (PAPD), the Special Grants for Leading Principal Investigators (LJ200908) from Jiangsu Administration of Traditional Chinese Medicine, and the Jiangsu Provincial Special Program of Medical Science (BL2014100).

\section{References}

1. Siegel R, Desantis C and Jemal A: Colorectal cancer statistics, 2014. CA Cancer J Clin 64: 104-117, 2014.

2. Nosher JL, Ahmed I, Patel AN, Gendel V, Murillo PG, Moss R and Jabbour SK: Non-operative therapies for colorectal liver metastases. J Gastrointest Oncol 6: 224-240, 2015.

3. Jawed I, Wilkerson J, Prasad V, Duffy AG and Fojo T: Colorectal cancer survival gains and novel treatment regimens: A systematic review and analysis. JAMA Oncol 1: 787-795, 2015.

4. Chang ST, Chen PF and Chang SC: Antibacterial activity of leaf essential oils and their constituents from Cinnamomum osmophloeum. J Ethnopharmacol 77: 123-127, 2001.
5. Koh WS, Yoon SY, Kwon BM, Jeong TC, Nam KS and Han MY: Cinnamaldehyde inhibits lymphocyte proliferation and modulates T-cell differentiation. Int J Immunopharmacol 20: 643-660, 1998

6. Ka H, Park HJ, Jung HJ, Choi JW, Cho KS, Ha J and Lee KT: Cinnamaldehyde induces apoptosis by ROS-mediated mitochondrial permeability transition in human promyelocytic leukemia HL-60 cells. Cancer Lett 196: 143-152, 2003.

7. López P, Sánchez C, Batlle R and Nerín C: Solid- and vaporphase antimicrobial activities of six essential oils: Susceptibility of selected foodborne bacterial and fungal strains. J Agric Food Chem 53: 6939-6946, 2005.

8. Imai T, Yasuhara K, Tamura T, Takizawa T, Ueda M, Hirose M and Mitsumori K: Inhibitory effects of cinnamaldehyde on 4-(methylnitrosamino)-1-(3-pyridyl)-1-butanone-induced lung carcinogenesis in rasH2 mice. Cancer Lett 175: 9-16, 2002.

9. Huang TC, Chung YL, Wu ML and Chuang SM: Cinnamaldehyde enhances Nrf2 nuclear translocation to upregulate phase II detoxifying enzyme expression in HepG2 cells. J Agric Food Chem 59: 5164-5171, 2011.

10. Wu SJ, Ng LT and Lin CC: Effects of vitamin E on the cinnamaldehyde-induced apoptotic mechanism in human PLC/PRF/5 cells. Clin Exp Pharmacol Physiol 31: 770-776, 2004.

11. Chew EH, Nagle AA, Zhang Y, Scarmagnani S, Palaniappan P, Bradshaw TD, Holmgren A and Westwell AD: Cinnamaldehydes inhibit thioredoxin reductase and induce Nrf2: Potential candidates for cancer therapy and chemoprevention. Free Radic Biol Med 48: 98-111, 2010.

12. Suman S, Kurisetty V, Das TP, Vadodkar A, Ramos G, Lakshmanaswamy R and Damodaran C: Activation of AKT signaling promotes epithelial-mesenchymal transition and tumor growth in colorectal cancer cells. Mol Carcinog 53 (Suppl 1): E151-E160, 2014

13. Johnson SM, Gulhati P, Rampy BA, Han Y, Rychahou PG, Doan HQ, Weiss HL and Evers BM: Novel expression patterns of PI3K/A kt/mTOR signaling pathway components in colorectal cancer. J Am Coll Surg 210: 767-778, 2010.

14. Osaki M, Oshimura M and Ito H: PI3K-Akt pathway: Its functions and alterations in human cancer. Apoptosis 9: 667-676, 2004.

15. Vivanco I and Sawyers CL: The phosphatidylinositol 3-kinase AKT pathway in human cancer. Nat Rev Cancer 2: 489-501, 2002.

16. Li Y, Wang SJ, Xia W, Rahman K, Zhang Y, Peng H, Zhang H and Qin LP: Effects of tatariside G isolated from Fagopyrum tataricum roots on apoptosis in human cervical cancer HeLa cells. Molecules 19: 11145-11159, 2014.

17. Xu C, Sun G, Yuan G, Wang R and Sun X: Effects of platycodin $\mathrm{D}$ on proliferation, apoptosis and PI3K/Akt signal pathway of human glioma U251 cells. Molecules 19: 21411-21423, 2014.

18. Hulkower KI and Herber RL: Cell migration and invasion assays as tools for drug discovery. Pharmaceutics 3: 107-124, 2011.

19. Wu N, Luo J, Jiang B, Wang L, Wang S, Wang C, Fu C, Li J and Shi D: Marine bromophenol bis(2,3-dibromo-4,5-dihydroxyphenyl)-methane inhibits the proliferation, migration, and invasion of hepatocellular carcinoma cells via modulating ß1-integrin/FAK signaling. Mar Drugs 13: 1010-1025, 2015.

20. Li Y, Gu JF, Zou X, Wu J, Zhang MH, Jiang J, Qin D, Zhou JY, Liu BX, Zhu YT, et al: The anti-lung cancer activities of steroidal saponins of $P$. polyphylla Smith var. chinensis (Franch.) Hara through enhanced immunostimulation in experimental Lewis tumor-bearing C57BL/6 mice and induction of apoptosis in the A549 cell line. Molecules 18: 12916-12936, 2013.

21. Zinkel S, Gross A and Yang E: BCL2 family in DNA damage and cell cycle control. Cell Death Differ 13: 1351-1359, 2006.

22. Gupta S, Afaq F and Mukhtar H: Involvement of nuclear factor-kappa B, Bax and Bcl-2 in induction of cell cycle arrest and apoptosis by apigenin in human prostate carcinoma cells. Oncogene 21: 3727-3738, 2002.

23. Bae GY, Choi SJ, Lee JS, Jo J, Lee J, Kim J and Cha HJ: Loss of E-cadherin activates EGFR-MEK/ERK signaling, which promotes invasion via the ZEB1/MMP2 axis in non-small cell lung cancer. Oncotarget 4: 2512-2522, 2013.

24. Park KS, Kim SJ, Kim KH and Kim JC: Clinical characteristics of $T I M P 2, M M P 2$, and $M M P 9$ gene polymorphisms in colorectal cancer. J Gastroenterol Hepatol 26: 391-397, 2011.

25. Cavdar Z, Canda AE, Terzi C, Sarioglu S, Fuzun M and Oktay G: Role of gelatinases (matrix metalloproteinases 2 and 9), vascular endothelial growth factor and endostatin on clinicopathological behaviour of rectal cancer. Colorectal Dis 13: 154-160, 2011. 
26. Bauvois B: New facets of matrix metalloproteinases MMP-2 and MMP-9 as cell surface transducers: Outside-in signaling and relationship to tumor progression. Biochim Biophys Acta 1825: 29-36, 2012.

27. Wang H, Duan L, Zou Z, Li H, Yuan S, Chen X, Zhang Y, Li X, Sun $\mathrm{H}$, Zha H, et al: Activation of the PI3K/Akt/mTOR/p70S6K pathway is involved in S100A4-induced viability and migration in colorectal cancer cells. Int J Med Sci 11: 841-849, 2014.

28. Ryu YL, Jung KH, Son MK, Yan HH, Kim SJ, Shin S, Hong S and Hong SS: Anticancer activity of HS-527, a novel inhibitor targeting PI3-kinase in human pancreatic cancer cells. Cancer Lett 353: 68-77, 2014.

29. Zhang X, Li XR and Zhang J: Current status and future perspectives of PI3K and mTOR inhibitor as anticancer drugs in breast cancer. Curr Cancer Drug Targets 13: 175-187, 2013.

30. Elumalai P, Arunkumar R, Benson CS, Sharmila G and Arunakaran J: Nimbolide inhibits IGF-I-mediated PI3K/Akt and MAPK signalling in human breast cancer cell lines (MCF-7 and MDA-MB-231). Cell Biochem Funct 32: 476-484, 2014.

31. Yamaguchi K, Lee SH, Kim JS, Wimalasena J, Kitajima S and Baek SJ: Activating transcription factor 3 and early growth response 1 are the novel targets of LY294002 in a phosphatidylinositol 3-kinase-independent pathway. Cancer Res 66: 2376-2384, 2006.

32. Samani AA, Yakar S, LeRoith D and Brodt P: The role of the IGF system in cancer growth and metastasis: Overview and recent insights. Endocr Rev 28: 20-47, 2007.

33. Mitsiades CS, Mitsiades N, Poulaki V, Schlossman R, Akiyama M, Chauhan D, Hideshima T, Treon SP, Munshi NC, Richardson PG, et al: Activation of NF-kappaB and upregulation of intracellular anti-apoptotic proteins via the IGF-1/Akt signaling in human multiple myeloma cells: Therapeutic implications. Oncogene 21 5673-5683, 2002.

34. Hanahan D and Weinberg RA: Hallmarks of cancer: The next generation. Cell 144: 646-674, 2011.

35. Zhou L, Lu Y, Yang G and Wu J: Research on tumorigenicity of cinnamaldehyde in melanoma cell lines and its mechanism. Tumour Biol 35: 5717-5722, 2014.

36. Yun M, Lee D, Park MN, Kim EO, Sohn EJ, Kwon BM and Kim SH: Cinnamaldehyde derivative (CB-PIC) sensitizes chemoresistant cancer cells to drug-induced apoptosis via suppression of MDR1 and its upstream STAT3 and AKT signalling. Cell Physiol Biochem 35: 1821-1830, 2015.

37. Liao BC, Hsieh CW, Liu YC, Tzeng TT, Sun YW and Wung BS: Cinnamaldehyde inhibits the tumor necrosis factor-alphainduced expression of cell adhesion molecules in endothelial cells by suppressing NF-kappaB activation: Effects upon IkappaB and Nrf2. Toxicol Appl Pharmacol 229: 161-171, 2008.

38. Matthews GM, Newbold A and Johnstone RW: Intrinsic and extrinsic apoptotic pathway signaling as determinants of histone deacetylase inhibitor antitumor activity. Adv Cancer Res 116: 165-197, 2012.
39. Jagtap P and Szabó C: Poly(ADP-ribose) polymerase and the therapeutic effects of its inhibitors. Nat Rev Drug Discov 4: 421-440, 2005

40. Soldani C and Scovassi AI: Poly(ADP-ribose) polymerase-1 cleavage during apoptosis: An update. Apoptosis 7: 321-328, 2002.

41. Su CC, Chen JY, Din ZH, Su JH, Yang ZY, Chen YJ, Wang RY and $\mathrm{Wu} \mathrm{YJ}$ : 13-Acetoxysarcocrassolide induces apoptosis on human gastric carcinoma cells through mitochondria-related apoptotic pathways: p38/JNK activation and PI3K/AKT suppression. Mar Drugs 12: 5295-5315, 2014.

42. Reed JC: Regulation of apoptosis by bcl-2 family proteins and its role in cancer and chemoresistance. Curr Opin Oncol 7: 541-546, 1995.

43. Yin C, Knudson CM, Korsmeyer SJ and Van Dyke T: Bax suppresses tumorigenesis and stimulates apoptosis in vivo. Nature 385: 637-640, 1997.

44. Yates CM, McGettrick HM, Nash GB and Rainger GE: Adhesion of tumor cells to matrices and endothelium. Methods Mol Biol 1070: 57-75, 2014.

45. Liu SQ, Su YJ, Qin MB, Mao YB, Huang JA and Tang GD: Sphingosine kinase 1 promotes tumor progression and confers malignancy phenotypes of colon cancer by regulating the focal adhesion kinase pathway and adhesion molecules. Int J Oncol 42: 617-626, 2013.

46. Gao XH, Yang XQ, Wang BC, Liu SP and Wang FB: Overexpression of twist and matrix metalloproteinase-9 with metastasis and prognosis in gastric cancer. Asian Pac J Cancer Prev 14: 5055-5060, 2013

47. Samuels $Y$ and Ericson K: Oncogenic PI3K and its role in cancer. Curr Opin Oncol 18: 77-82, 2006.

48. Richardson CJ, Schalm SS and Blenis J: PI3-kinase and TOR: PIKTORing cell growth. Semin Cell Dev Biol 15: 147-159, 2004.

49. Dunlap J, Le C, Shukla A, Patterson J, Presnell A, Heinrich MC, Corless CL and Troxell ML: Phosphatidylinositol-3-kinase and AKT1 mutations occur early in breast carcinoma. Breast Cancer Res Treat 120: 409-418, 2010.

50. Paradiso A, Mangia A, Azzariti A and Tommasi S: Phosphatidylinositol 3-kinase in breast cancer: Where from here? Clin Cancer Res 13: 5988-5990, 2007.

51. Wu Y, Yakar S, Zhao L, Hennighausen L and LeRoith D: Circulating insulin-like growth factor-I levels regulate colon cancer growth and metastasis. Cancer Res 62: 1030-1035, 2002.

52. Akagi Y, Liu W, Zebrowski B, Xie K and Ellis LM: Regulation of vascular endothelial growth factor expression in human colon cancer by insulin-like growth factor-I. Cancer Res 58: 4008-4014, 1998. 